\title{
Smart Hydrogel Particles: Biomarker Harvesting: One-step affinity purification, size exclusion, and protection against degradation
}

\author{
Alessandra Luchini ${ }^{1,2}$, David H. Geho ${ }^{2}$, Barney Bishop ${ }^{3}$, Duy Tran ${ }^{2}$, Cassandra Xia $^{2}$, Robert \\ Dufour $^{2}$, Clint Jones ${ }^{2}$, Virginia Espina ${ }^{2}$, Alexis Patanarut ${ }^{3}$, Weidong Zhu ${ }^{2}$, Mark Ross ${ }^{2}$, \\ Alessandra Tessitore ${ }^{2}$, Emanuel Petricoin III2 , and Lance A. Liotta ${ }^{2}$ \\ ${ }^{1}$ CRO-IRCCS National Cancer Institute, Aviano, Italy. \\ ${ }^{2}$ Center for Applied Proteomics and Molecular Medicine, George Mason University, Manassas, VA. \\ ${ }^{3}$ Department of Chemistry and Biochemistry, George Mason University, Manassas, VA.
}

\begin{abstract}
Disease-associated blood biomarkers exist in exceedingly low concentrations within complex mixtures of high-abundance proteins such as albumin. We have introduced an affinity bait molecule into $\mathrm{N}$-isopropylacrylamide to produce a particle that will perform three independent functions within minutes, in one step, in solution: a) molecular size sieving b) affinity capture of all solution phase target molecules, and c) complete protection of harvested proteins from enzymatic degradation. The captured analytes can be readily electroeluted for analysis.
\end{abstract}

\begin{abstract}
There is an urgent need to discover novel biomarkers that provide sensitive and specific disease detection 1 ,2. Cancer is rapidly becoming the leading cause of death for many population groups in the United States, largely due to the fact that the disease is usually diagnosed after the cancer has metastasized and treatment is ineffective. It is widely believed that early detection of cancer prior to metastasis will lead to a dramatic improvement in treatment outcome. Biomarkers are nucleic acids, proteins, protein fragments or metabolites indicative of a specific biological state, that are associated with the risk of contraction or presence of disease3. Biomarker research has revealed that low-abundance circulating proteins and peptides present a rich source of information regarding the state of the organism as a whole ${ }^{4}$. Two major hurdles have prevented these discoveries from reaching clinical benefit: 1) disease-relevant biomarkers in blood or body fluids may exist in exceedingly low concentrations within a complex mixture of biomolecules and could be masked by high-abundance species such as albumin, and 2) degradation of protein biomarkers can occur immediately following the collection of blood or body fluid as a result of endogenous or exogenous proteinases. The goal of this study was to create "smart" nano-particles that allow enrichment and encapsulation of selected classes of proteins and peptides from complex mixtures of biomolecules such as plasma, and protect them from degradation during subsequent sample handling. The captured analytes can be readily extracted from the particles by electrophoresis allowing for subsequent quantitative analysis. This nanotechnology provides a powerful tool that is uniquely suited for the discovery of novel biomarkers for early stage diseases such as cancer.
\end{abstract}

SUPPORTING INFORMATION AVAILABLE: Available in the Supplementary Information are details on particles synthesis protocol, SDS PAGE analysis on molecular sieving properties and enzymatic degradation, and tables (Table S1 and S2) listing proteins (with peptide coverage lists) identified via LC-MS/MS (ESI) on material electroeluted from NIPAm and NIPAm/AAc particles. This material is available free of charge via the Internet at http://pubs.acs.org. 
The concentration of proteins and peptides comprising the complex circulatory proteome ranges from $10^{-12} \mathrm{mg} / \mathrm{mL}$ to $10^{-3} \mathrm{mg} / \mathrm{mL}$, spanning ten orders of magnitude, with a few high molecular weight proteins such as albumin and immunoglobulins accounting for $90 \%$ of total protein content ${ }^{5}$. However, the low abundance and low molecular weight proteins and metabolites also present in the blood provide a wealth of information and have great promise as a source of new biomarkers. Conventional methods, such as two dimensional gel electrophoresis, do not have the sensitivity and resolution to detect and quantify low abundance low molecular weight proteins and metabolites. In spite of the moderately high sensitivity of modern mass spectrometers (attomolar concentration), their working range spans over threefour orders of magnitude and therefore the less abundant proteins are masked by more abundant proteins. Consequently, usual sample preparation steps for mass spectrometry (MS) experiments begin with depletion of high abundant proteins using commercially available immunoaffinity depletion columns (Agilent, Sigma, and Beckman-Coulter). After depletion, fractionation is performed by means of size exclusion chromatography, ion exchange chromatography, and/or isoelectric focusing. However, removal of abundant native high molecular weight proteins can significantly reduce the yield of candidate biomarkers because it has been recently shown that the vast majority of low abundance biomarkers are noncovalently and endogenously associated with the carrier proteins that are being removed ${ }^{6-} 9$. Methods, such as size exclusion ultrafiltration under denaturing conditions10, continuous elution denaturing electrophoresis 11 , or fractionation of serum by means of nanoporous substrates ${ }^{12}$ have been proposed to solve this problem. Moreover, these same recent findings point to the low molecular weight region of the proteome, as a rich and untapped source of biomarker candidates ${ }^{13-15}$.

In addition to the difficulties associated with the harvest and enrichment of candidate biomarkers from complex natural protein mixtures (such as blood), the stability of these potential biomarkers poses a challenge. Immediately following blood procurement (e.g. by venipuncture) proteins in the serum become susceptible to degradation by endogenous proteases or exogenous environmental proteases, such as proteases associated with the blood clotting process, enzymes shed from blood cells, or associated with bacterial contaminants. Therefore, candidate diagnostic biomarkers in the blood may be subjected to degradation during transportation and storage. This becomes an even more important issue for the fidelity of biomarkers within large repositories of serum and body fluids that are collected from a variety of institutions and locations where samples may be shipped without freezing.

We evaluated the ability of hydrogel particles to perform directly, in one step and in solution, the partition, affinity separation, concentration, and stabilization of low molecular weight proteins in serum as a new rapid method for blood derived biomarker isolation and analysis. Hydrogels, by definition, are three-dimensional cross-linked polymeric networks that can imbibe large amounts of water ${ }^{16}$. They are usually formed through monomer polymerization in the presence of a cross-linking agent, which is typically a monomer with at least two polymerizable functional moieties. Gels can be categorized as non-responsive (simple polymeric networks dramatically swell upon exposure to water) or responsive gels (have added functionality and display changes in solvation in response to certain stimuli such as temperature $^{17}$, pH18, 19 , ionic strength20, light 21, 22, and electric field23). Poly (N-alkyl acrylamides) have been extensively studied with respect to their thermoresponsivity 16,24 with poly(N-isopropylacrylamide) (NIPAm) being one of the most strongly explored temperature sensitive hydrogels within this group. NIPAm containing particles are highly appealing for their potential biotechnological applications, because of their stability, uniformity, and versatility with regard to the ease of making physical-chemical modifications in the particles. NIPAm particles have been investigated for drug delivery slow release and targeted release, for solute desorption $25^{-} 36$, interaction with cells 26 , and coupling with oligodeoxyribonucleotides (OND) as a solid phase for hybridization27. Since the size and 
porosity can be controlled by temperature, the use of temperature treatment to control uptake and release of chemicals has been one of the most extensively characterized application of NIPAm particles as vectors for controlled drug delivery $28^{-} 34$.

In the present study, hydrogel particles containing an affinity bait and a defined porosity were developed and demonstrated to a) rapidly and in one step sequester the low molecular weight fraction of serum proteins, peptides and metabolites, b) remove and concentrate the target molecules from solution, and c) protect captured proteins from enzymatic degradation.

NIPAm based particles have been chosen because their high water content, broad range of tunable porosities, consistency and uniformity following synthesis, functional reconstitution following freeze-drying, and potential biocompatibility. By changing the percentage of cross linking agent and temperature, it is possible to control the particles size and the effective porosity. A significant advantage for the application studied here is the ability of these particles to rapidly uptake molecules because of their open structure, high water content, dual hydrophobic and hydrophilic chemical moieties that can be substituted in the polymer, and large surface area. This is a critical requirement for the goal of rapid harvesting of labile small proteins in solution and protecting the proteins from degradation. The small size, uniformity of particle dimension, and reproducibility from batch to batch, of NIPAm provide a special advantage for applications in flow cytometry.

\section{Hydrogel Particle Synthesis and Characterization}

Gel particles incorporating N-isopropylacrylamide (NIPAm) were created and evaluated for molecular sieving properties. A second class of particles containing both NIPAm and acrylic acid (AAc), NIPAm/AAc, were fabricated to incorporate a charge-based affinity bait into the particles ${ }^{16,} 18,35$. Particle synthesis chemistry is described in the Supplementary Information.

Particle size dependence on temperature and $\mathrm{pH}$ were determined via Photon Correlation Spectroscopy (PCS, Submicron Particle Size Analyzer, Beckman Coulter). Average values were calculated for 3 measurements using a 200 second integration time, and the solutions were allowed to thermally equilibrate for 10 minutes before each set of measurements. Measured values were then converted to particle sizes via the Stokes-Einstein relationship ${ }^{36}$. NIPAm particle size decreased with increasing temperature (Figure 2A), which is a distinctive characteristic of thermo responsive hydrogels $28-33$. The NIPAm/AAc particles showed a similar temperature dependence with respect to particle size, however they also demonstrated a pH dependent behavior (Figure 2B). At low pH (3.5) AAc groups are protonated and NIPAm/ AAc particle size dependence on temperature is similar to underivatized particles. At higher $\mathrm{pH}$ (4.5 and 6.5) AAc groups are partially deprotonated and the average particle size increases, likely due to Coulombic interaction between polymeric chain and osmotic pressure resulting from counter ion ingress in particles 37,38 .

Particles were further characterized by atomic force microscopy (AFM) using an NSCRIPTOR ${ }^{\mathrm{TM}}$ DPN $^{\circledR}$ System (NanoInk). Images were acquired under AC mode using a silicon tip with a typical resonance frequency of $300 \mathrm{kHz}$ and a radius smaller than $10 \mathrm{~nm}$. Aliquots of $1 \% \mathrm{w} / \mathrm{v}$ particles $(50 \mu \mathrm{L})$ were deposited on freshly cleaved mica; samples were incubated for ten minutes in humid atmosphere at room temperature to allow deposition, and then dried under nitrogen flow. AFM images of these particles (Figure 2C and 2D) show them to be homogeneous in size, and with particle diameters consistent with those measured with light scattering. 


\section{Molecular Sieving by Hydrogel Particles}

NIPAm particles were tested for their molecular sieve performance in solution as schematically presented in Figure 3; the goal being to create particles that could capture proteins and small molecules with molecular weights less than 20,000 Da since the peptidome is thought to contain a rich source of biomarkers ${ }^{13-15}$.

This size range contains informative proteins, peptides and metabolites that are difficult, if not impossible, to separate from complex protein mixtures (such as serum or plasma) with adequate yield using 2-D gel electrophoresis or column chromatography. The degree of cross-linking within the particle enabled exclusion of albumin and other high abundance large molecules while capturing molecules with sizes smaller than the cut-off pore size of the particles. Particles with varied degrees of cross-linking were investigated until one was identified that demonstrated an effective 20,000 Da exclusive pore size. These particles were further studied in order to evaluate their sieving efficiency and nonspecific binding of excluded molecules to the particle surface. Because serum albumin is present in large excess $\left(10^{6}-10^{9}\right.$ fold) relative to the proteins and peptides of interest, it was necessary to examine the efficiency and completeness of albumin exclusion.

Two independent methods were used to measure sieving performance: flow cytometry and gel electrophoresis. Aliquots of NIPAm particles $(50 \mu \mathrm{L}, 10 \mathrm{mg} / \mathrm{mL})$ were incubated with target molecular species, and centrifuged to collect the particles $\left(7\right.$ minutes, $\left.25^{\circ} \mathrm{C}, 16,100 \mathrm{rcf}\right)$. The supernatant was removed and the particles were re-suspended in $1 \mathrm{~mL}$ water. Centrifugation and washing were repeated three times and the fluorescent intensity of the particles was measured using a FACScan flow cytometer (Becton Dickinson). The background fluorescent signal of untreated particles in water was used as a reference for all measurements. Fluorescein isothiocyanate (FITC, MW $389 \mathrm{Da}$ ) was used as a model to study small molecule uptake and the dependence of uptake on incubation time and concentration. Particles incubated with various concentrations of FITC $(5 \mu \mathrm{M}, 20 \mu \mathrm{M}$, and $100 \mu \mathrm{M})$ showed a dose dependent uptake rate (Figure 4A) toward saturation. Time course studies demonstrated that FITC uptake could occur rapidly (5 minutes, Figure 4B) at $10 \%$ v/v particles concentration.

NIPAm particles were also incubated with FITC-labeled bovine serum albumin (BSA), MW 66,000 Da, with a dye:molecule ratio of 1:1 (FITC-BSA, Sigma), FITC labeled insulin MW 3,500 Da, with a dye:molecule ratio of 1:7 (Invitrogen), or FITC labeled myoglobin MW $17,000 \mathrm{Da}$, with a dye:molecule ratio of 1.36. Myoglobin (Sigma) was FITC labeled by means of the HOOK - Dye Labeling Kit (G Bioscience) in accordance of the vendor's instructions. Concentrations of all fluorescent species were adjusted in order to equalize the fluorescence signal.

As shown in Figure 5A and 5B particles incubated with FITC-BSA (MW 66,000 Da) have no detectable shift in fluorescence signal relative to the particle background fluorescence, which indicates no detectable BSA uptake or non specific binding by the particles. On the other hand, incubation with FITC-insulin (MW 3,500 Da) results in a right shift in fluorescence relative to the control, confirming the uptake of insulin by the particles. FITC alone (MW $389 \mathrm{Da}$ ), a molecule in the size range of many metabolites, and FITC-myoglobin (MW 17,000 Da), another protein below the effective size cut-off of the particles, were both rapidly captured.

These findings were confirmed by SDS-PAGE analysis. The particles were directly loaded on the gel after incubation with protein solution and washing. Insulin (Figure 5C), and myoglobin (Figure 5D) were trapped by particles, while BSA was totally excluded (Figure 5D). 


\section{Incorporation of a Charged Bait in the Molecular Sieving Particles Significantly Enhances Uptake}

Passive molecular sieving cannot effectively harvest and concentrate all of the target proteins in solution because the concentration of the captured target protein in the particles is dependent on the equilibrium between rates of proteins exiting and entering particles and the concentration of the target protein in the bulk solution. Consequently particles were constructed that incorporated an affinity bait to facilitate harvesting of target proteins and prevent the captured proteins from exiting the particle.

A negatively-charged moiety was selected as a bait for proteins and molecules that have a positive net charge. Incorporation of a negatively-charged bait within the particles would allow the particles to preferentially sequester and concentrate positively-charged proteins, peptides and other biomolecules. Therefore, particles were prepared based on a NIPAm/AAc copolymer, which carries a large net negative charge at $\mathrm{pH}$ values greater than 3.5. As shown schematically in Figure 6, the presence of charged bait, in principle, should enhance substantially the $\mathrm{K}_{\mathrm{eq}}$ and thereby achieve a significantly higher concentration of the target protein inside the particle compared to the solution outside the particle.

As shown in Figure 7A, NIPAm/AAc particles concentrated analytes from solution with substantially greater efficiency relative to underivatized NIPAm particles. Suspensions of NIPAm and NIPAm/AAc particles $(10 \mathrm{mg} / \mathrm{mL})$ were incubated for 1 hour with myoglobin (MW 17,000 Da, $20 \mu \mathrm{M}$ in water). Following incubation with NIPAm particles, significant levels of myoglobin remained in the bulk solution with some protein being bound by the particles, which lack the anionic affinity bait (Figure 7A). Following incubation with NIPAm/ AAc particles, which contain the anionic affinity bait, all of the myoglobin had been captured by the NIPAm/AAc particles, with no detectable myoglobin remaining in bulk solution. Correlating myoglobin band intensity for serial dilutions of NIPAm/AAc particles with that of NIPAm particles suggests that the NIPAm/AAc particles sequestered myoglobin with more than 128 -fold greater efficiency compared with particles that lack the affinity bait.

In order to demonstrate that the superior protein uptake associated with NIPAm/AAc particles was charge driven, aliquots of a solution containing myoglobin $(20 \mu \mathrm{M})$ and BSA $(20 \mu \mathrm{M})$ were incubated with NIPAm/AAc particles in phosphate buffer titrated to either $\mathrm{pH} 5.5 \mathrm{or} \mathrm{pH}$ 8 (Figure 7B). Particles were separated by centrifugation and washed three times with MilliQ water, as described above. At pH 5.5, myoglobin ( $\mathrm{pI} 7$ ) is expected to be positively charged, and electrostatic interactions between the protein and the negatively charged carboxyl groups of NIPAm/AAc particles would be attractive. However at $\mathrm{pH} 8$, myoglobin would be negatively charged, and any electrostatic interactions with the anionic particles would likely be repulsive in nature. Consistent with these expectations, myoglobin was efficiently sequestered by NIPAm/AAc particles at $\mathrm{pH} 5.5$ where the protein and the particles have opposite net charges, and no myoglobin was detectable in particles that had been incubated with myoglobin at $\mathrm{pH} 8$ (Figure 7B).

The efficiency of NIPAm/AAc affinity baited particles to bind and concentrate proteins and peptides with MW less than ca. 20,000 Da is illustrated in Figure 8A. NIPAm/AAc and NIPAm particles were each incubated for 1 hour with lysozyme $(20 \mu \mathrm{M})$ and BSA $(20 \mu \mathrm{M})$ in Tris $(\mathrm{pH}$ $7,50 \mathrm{mM}$ ). The particles then were washed with three $1 \mathrm{~mL}$ volumes of water, and the captured proteins were electro-eluted onto an SDS polyacrylamide gel.

While the NIPAm/AAc particles appeared to have captured all of the lysozyme present in the solution, there was no indication that BSA had been bound non-specifically by the particles. 
As was observed with myoglobin, NIPAm particles, lacking the affinity bait, did not appear to significantly concentrate lysozyme.

A solution of protein molecular weight markers was used to further assess the molecular weight cut off (MWCO) of the proteins sequestered by the particles (Figure 8B). The solution consisted of $0.5 \mathrm{mg} / \mathrm{mL}$ of each of the following proteins: aprotinin (MW 6,500 Da, Sigma-Aldrich), lysozyme (MW 14,400 Da, Sigma-Aldrich), trypsin inhibitor (MW 21,500 Da, Invitrogen), carbonic anhydrase (MW 31,000 Da, Sigma-Aldrich), ovalbumin (MW 45,000 Da, SigmaAldrich), and BSA (MW 66,000 Da, Fisher Scientific) dissolved in Tris (pH 7, $50 \mathrm{mM}$ ). It was found that NIPAm/AAc baited particles, incubated with the protein solution, effectively captured and concentrated all protein molecules with MW less than ca. 21,500 Da, and did not bind any proteins with MW greater than 21,500 Da. NIPAm particles showed a similar MWCO with MW $<=14,400 \mathrm{Da}$ or smaller and not binding proteins MW >=14,400 Da. The MWCO resolution achieved with NIPAm/AAc and NIPAm particles compares favorably, or exceeds, that associated with standard molecular sieving chromatography ${ }^{39}$. In order to further indagate molecular sieving properties of the beads, NIPAm/AAc particles were incubated with platelet derived growth factor B $(0.003 \mathrm{mg} / \mathrm{mL}, 14,500 \mathrm{Da}$, Cell Signaling) and BSA $(0.067 \mathrm{mg} / \mathrm{mL})$ in Tris $(100 \mathrm{mM} \mathrm{pH} \mathrm{7)}$ for one hour. Washing procedure was the same as described before. SDS PAGE in Figure 9 shows complete PDGF uptake and BSA exclusion. PDGF is a representative model for low abundance low molecular weight protein present in the blood and PDGF-B concentration in blood is $3.3 \mathrm{ng} / \mathrm{mL}^{40}$.

All the incubations presented in this study were conducted at room temperature if not otherwise specified since it is representative of real world conditions. Nevertheless, because of the drastic change in size particles undergo when the temperature of solution is altered, temperature effects on MWCO were investigated. The solution of molecular weight markers described above was incubated with NIPAm/AAc particles at 4 and $40^{\circ} \mathrm{C}$ and the MWCO was approximately 10,000 Da higher at $4{ }^{\circ} \mathrm{C}$ with respect to $40{ }^{\circ} \mathrm{C}$ (data not shown).

Based on these results, we next tested the ability of the particles to capture small molecules spiked in complex solutions such as serum to mimic real-world biomarker discovery and analysis type experiments. Aliquots of FITC-labeled insulin (final concentration $40 \mu \mathrm{M}$ ) in 1:10 diluted serum were incubated with NIPAm and NIPAm/AAc particles. Flow cytometry analysis demonstrated that NIPAm particles incubated in serum containing FITC-insulin yielded a right shift in fluorescence intensity relative to control particles and particles incubated with serum alone (Figure 10A).

This result clearly demonstrated the ability of NIPAm particles to capture insulin from a complex matrix such as serum. However, the capture efficiency of the NIPAm particles incubated with a simple aqueous solution containing only insulin was higher than that attained with serum incubated NIPAm particles. While the two classes of particles exhibited a similar uptake of insulin in an aqueous solution, the particles with the charged bait were more efficient in capturing insulin spiked into serum compared to the underivatized particles. (Figure 10B).

Time courses uptake studies for NIPAm and NIPAm/AAc particles incubated with FITClabeled insulin ( $\mathrm{pI}$ 5.3) were conducted in order to confirm and extend the data obtained for the small molecule, FITC. Histograms of fluorescence intensity associated with Flow cytometry analyses of NIPAm and NIPAm/AAc particles incubated with FITC-labeled insulin collected at different time intervals are reported in Figure 11. This data indicates that sequestration occurs rapidly (5 minutes) and constant over time. 


\section{Rapid time course of target protein uptake by bait containing particles}

In order to prove that the kinetics of protein uptake is very rapid, the amount of protein remaining in bulk solution after incubation with NIPAm/AAc particles was measured by Reverse Phase Protein Arrays (RPPA) ${ }^{41}$. RPPA was chosen as a means to determine protein concentration in particles supernatant since it is a very sensitive technique (more sensitive by three orders of magnitude than methods like Bradford assays) and our goal was to use diluted protein solution in order to mimic the condition of low abundance low molecular weight proteins in the blood, and to demonstrate how complete protein removal from bulk solution was. Different amounts of NIPAm/AAc particles (1.15 and 11.5 million) were incubated with lysozyme $(20 \mu \mathrm{M})$ in Tris $(\mathrm{pH} 7,50 \mathrm{mM})$ in a total volume of $100 \mu \mathrm{L}$ for periods of 1 and 10 minutes. After centrifugation of the particles, aliquots of supernatant were spotted on a nitrocellulose coated slide (FAST slide, Whatman) using an Aushon 2470 robotic arrayer (Aushon Biosystems). Arrays were stained with a colloidal gold solution, AuroDye Forte Kit (Amersham), images were acquired using a PowerLook 1120 scanner (Umax), and numeric values were obtained from images with ImageQuant (GE Healthcare) and processed with SigmaPlot (Systat). The bulk solution after a one minute incubation with 1.15 million particles contained $28 \%$ of the initial protein amount, and $15 \%$ after ten minutes. Moreover, the solution recovered from incubation with 11.5 million particles after 1 and 10 minutes contained 5\% and $9 \%$ of the initial amount, respectively (Figure 12A). To be noted is that, since in all the time course experiments the separation of particles from solution was obtained by centrifugation, reported time values refer to incubations time intervals only. Beyond that, particles were in contact with solution for additional 7 minutes required by centrifugation.

The kinetics of protein uptake by NIPAm/AAc particles was further investigated by incubating particles with BSA $(20 \mu \mathrm{M})$ and lysozyme $(20 \mu \mathrm{M})$ in Tris $(\mathrm{pH} 7,50 \mathrm{mM})$ at room temperature and using SDS-PAGE to monitor lysozyme uptake at time points of 1, 10, 20,30, and 60 minutes (Figure 12B). The results of this experiment showed that lysozyme sequestration was nearly complete after 1 minute and was complete by 60 minutes, confirming that the process occurs very quickly as indicated in the flow cytometry time course study described above. As expected, BSA was excluded by the particles, and none of the BSA was taken-up by the NIPAm/AAc throughout the duration of the experiment (60 minutes).

\section{Demonstration of Isolation and Enrichment of Low Molecular Weight and Low Abundance Analytes from Serum}

The ability of NIPAM and NIPAm/AAc particles to sequester and concentrate low concentration candidate protein biomarkers from serum for proteomic analysis was evaluated by incubating the particles with a 1:10 v/v dilution of serum in water for 1 hour. The trapped proteins were electrophoretically eluted from the particles under denaturing conditions and then trypsin digested. The particles were heated in SDS sample buffer for 5 minutes at $100^{\circ}$ $\mathrm{C}$ and loaded on a 4-20\% Tris Glicine gel (Invitrogen). Bands below $30 \mathrm{kDa}$ were cut and ingel trypsin digestion was performed ${ }^{11}$. The resulting peptide fragments were analyzed by online liquid chromatography/electrospray ionization tandem mass spectrometry (LC/ESI MS) using LTQ-Orbitrap mass spectrometer (Thermo Fisher). Reverse phase column was slurrypacked in-house with $5 \mu \mathrm{m}, 20 \AA$ A pore size C18 resin (Michrom BioResources, CA) in 100 $\mathrm{mm}$ i.d. $\times 10 \mathrm{~cm}$ long fused silica capillary (Polymicro Technologies, Phoenix, AZ) with a laser-pulled tip. After sample injection, the column was washed for 5 minutes with mobile phase A ( $0.1 \%$ formic acid) and peptides were eluted using a linear gradient of $0 \%$ mobile phase B ( $0.1 \%$ formic acid, $80 \%$ acetonitrile) to $50 \%$ mobile phase B in 50 minutes at $200 \mathrm{nl} /$ min, then to $100 \%$ B in an additional 5 minutes. The LTQ mass spectrometer was operated in a data-dependent mode in which each full MS scan was followed by five MS/MS scans were the five most abundant molecular ions were dynamically selected and fragmented by collision- 
induced dissociation (CID) using a normalized collision energy of 35\%. MS/MS data were matched against the NCBI (National Center for Biotechnology Information) human protein database with the program SEQUEST (Bioworks software, Thermo) using full tryptic cleavage constraints. High-confidence peptide identifications were obtained by applying the following filters to the search results: cross-correlation score (XCorr) $>=1.9$ for $1+, 2.2$ for $2+, 3.5$ for $3+$, and a maximum probability for a random identification of 0.01 . The list of identified proteins (Supplementary Information) demonstrated that albumin and other high abundance serum proteins were not present in the particles. On the other hand, the list of identified proteins indicates that the particles sequestered rare and small-sized serum proteins and peptides.

\section{Protein Sequestration by Particle Blocks Protease Degradation}

One of the major problems associated with biological fluids is the potential for sample degradation during collection, transport, storage and analysis. Endogenous clotting cascade enzymes, enzymes released from damaged cells, or exogenous enzymes (from contaminating bacteria) can contribute to the degradation of diagnostically important proteins.

The lack of standardized preservation methods could result in bias in high-throughput analysis of serum and plasma ${ }^{42}$. While it was expected that proteases with MW greater than the MWCO of the particles $(\sim 20,000 \mathrm{Da})$ would be excluded from the interior space of the particles and thereby denied access to captured proteins, smaller proteases such as trypsin $(23,800 \mathrm{Da})$ are more likely to be able to enter the particles. Additionally, it was not known whether proteases that entered charged-bait particles would retain their enzymatic potency when both the substrate proteins and the enzyme were sequestered by the particles (Figure 12). Therefore, NIPAm/AAc particles were incubated at $37^{\circ} \mathrm{C}$ in a pH $7 \mathrm{NH}_{4} \mathrm{HCO}_{3}(100 \mathrm{mM})$ solution containing lysozyme $(0.5 \mathrm{mg} / \mathrm{mL})$ and trypsin $(0.05 \mathrm{mg} / \mathrm{mL}$, Promega). Trypsin was selected for these studies based on its small size and the fact that the tryptic digestion of lysozyme would produce very characteristic cleavage products. The conditions used in this experiment would allow both lysozyme and trypsin to enter the particle. Analysis of the captured proteins by SDS PAGE after incubation for 1 hour and overnight showed only two bands - one corresponding to trypsin and the other to the full length lysozyme, indicating that no degradation of the protein had occurred (Figure 14A). Incubation of lysozyme $(0.5 \mathrm{mg} / \mathrm{mL})$ with trypsin $(0.05 \mathrm{mg} / \mathrm{mL})$ at $37^{\circ} \mathrm{C}$ in a pH $7 \mathrm{NH}_{4} \mathrm{HCO}_{3}(100 \mathrm{mM})$ solution in the absence of NIPAm/AAc particles resulted in degradation of lysozyme. SDS-PAGE analysis of the reaction after incubation for 1 hour and overnight clearly indicated the presence of low molecular weight peptide fragments, which showed that lysozyme was proteolyzed by trypsin in the absence of NIPAm/AAc particles. These results clearly indicate that sequestration of small proteins by affinity-bait particles can effectively shield bound proteins from proteases including those that are capable of entering the particles interior.

In order to better understand the benefits associated with sequestration of proteins by NIPAm/ AAc affinity-bait particles, NIPAm/AAc particles were incubated at $37^{\circ} \mathrm{C}$ with a combination of BSA $(0.5 \mathrm{mg} / \mathrm{mL})$, lysozyme $(0.5 \mathrm{mg} / \mathrm{mL})$ and trypsin $(0.05 \mathrm{mg} / \mathrm{mL})$ in $100 \mathrm{mM}$ $\mathrm{NH}_{4} \mathrm{HCO}_{3}(\mathrm{pH} 7)$.

As with the previous protection study, the reaction was analyzed using SDS-PAGE after incubating $1 \mathrm{hr}$ and overnight. In the absence of NIPAm/AAc particles, the majority of BSA had been digested after $1 \mathrm{hr}$ and the band corresponding to full-length BSA had disappeared after incubating overnight (Figure 14B). As was noted earlier, the NIPAm/AAC particles efficiently sequestered both lysozyme and trypsin, and protected lysozyme from proteolysis by trypsin. However, the particles did not bind BSA, and the presence of low molecular weight bands in the supernatant after 1 hour and overnight incubation accompanied by the decrease in intensity of the band corresponding to full-length BSA indicates that BSA was not protected 
from degradation by trypsin. Suppression of proteolytic activity by enzymes small enough to enter the particles, such as trypsin, may occur because immobilization of the enzymes by the charge-bait particle prevents them from binding substrate proteins or may be the result of steric hindrance associated with trapping of the substrate by the affinity-bait groups in the particle thus preventing enzymes from productively binding target proteins inside the particle. Thus, the functional state of the proteins sequestered by the charge-bait may be similar to that of proteins arrested using a precipitating fixative treatment.

In order to exclude that non specific interactions of analytes exist with the surface charge of particles we synthesized a batch of particles containing a NIPAm/AAc core covered by a NIPAm shell (details on protocol available in the Supplemental Information). We then confirmed that core shell particles have the same sieving properties as NIPAm/AAc particles (Figure S1).

The use of lysozyme in its native form is a model close to real physiological condition and make it possible to detect partial products of degradation with SDS PAGE analysis. With this model it was proved that bait particles are able to protect the protein from enzymatic degradation. Nevertheless, to verify how effective ${ }^{43}$ the protection from degradation of particles with bait is, we used reduced and alkylated lyzozyme and incubated it with trypsin and particles. Lysozyme was reduced by incubation with Dithiothreitol (DTT) $(10 \mathrm{mM})$ in $\mathrm{NH}_{4} \mathrm{HCO}_{3}$ buffer $(50 \mathrm{mM}, \mathrm{pH} 8)$ containing urea $(2 \mathrm{M})$ for one hour at room temperature. Iodoacetamide was added to the solution to a final concentration of $50 \mathrm{mM}$ and let react in the dark for 30 minutes. Lysozyme solution was diluted 1:2 with $\mathrm{NH}_{4} \mathrm{HCO}_{3}$ buffer $(50 \mathrm{mM}, \mathrm{pH}$ 8) to a final concentration of $0.5 \mathrm{mg} / \mathrm{ml}$. Aliquots of $50 \mu \mathrm{l}$ of reduced and alkylated lysozyme were added to $50 \mu \mathrm{l}$ of particles $(10 \mathrm{mg} / \mathrm{ml})$ in order to demonstrate that lysozyme by itself was captured by particles. In addition, trypsin was added to lysozyme solution at a w/w ratio of $1: 50(0.01 \mathrm{mg} / \mathrm{ml})$ and $1: 100(0.005 \mathrm{mg} / \mathrm{ml})$. Besides, particles with and without bait, and core shell particles were added to lysozyme-trypsin solution. All the solutions were incubated for 1 hour at $37^{\circ} \mathrm{C}$. Particles were washed as described above and all samples loaded on SDS PAGE. In Figure 15 it is shown that a) reduced and alkylated lysozyme undergoes to trypsin mediated proteolysis and products of degradation are too small to be detected (lane 1-3), b) lysozyme is captured by plain particles (lane 4) but in the presence of trypsin it is not protected from degradation as is evident from the fact that lysozyme band is absent in the particles (lane 6) and highly reduced in intensity in the supernatant (lane 5), c) particles with bait harvest and concentrate lysozyme (lane 7) and protect lysozyme from degradation (lane 9), d) likewise, core shell particles harvest, concentrate and protect reduced and alkylated lysozyme from tryptic degradation. This suggests that the AAc bait plays a fundamental role in protecting proteins from degradation.

An incubation of trypsin $\left(0.5 \mathrm{mg} / \mathrm{ml}\right.$ in $\mathrm{NH}_{4} \mathrm{HCO}_{3} 50 \mathrm{mM} \mathrm{pH} 8,1$ hour, $\left.37^{\circ} \mathrm{C}\right)$ with particles was performed to corroborate the entrance of the enzyme in the beads. Trypsin is captured by plain particles, and is captured and concentrated by NIPAm/AAc and core shell particles (Figure 16).

We have described the development and application of hydrogel bait-containing particles as a new tool for harvesting and concentrating small molecule analytes and biomarker candidates from biological fluids, allowing high throughput analysis of low-abundance and low molecular weight components. These nanoparticles present a rapid and straightforward workflow for direct utility in raw body fluids, while the work herein described the particles with a negative charge that preferentially bind cationic species, positively charged particles such as a NIPAm/ allylamine copolymer could be used to selectively harvest and concentrate anionic species from biological fluids. Similarly, hydrophobic metabolites could be captured for comprehensive metabolomic studies by using more hydrophobic particles such as NIPAm/styrene copolymers. 
Analyte-specific chemical or protein or nucleic acid affinity baits can be incorporated. For example, boronate-containing particles, which are known to bind saccharides, would be utilized to sequester glycoproteins from solution ${ }^{44}$. Consequently, NIPAm-allylamine copolymer are currently being synthesized that contain a bait for anionic proteins. Moreover, p-vinylphenylboronic acid (VPBA) is under consideration as a copolymer for harvesting of sugars and nucleic acids. Further affinity baits such as triazinil-based reactive dyes (that have affinity towards proteins), hexadecylamine (for lipids uptake) and cyclodextrins (able to associate small molecules) are being noncovalently or covalently immobilized within the particles. In particular, we have used the bait chemistry described above to harvest the following small metabolites L-Dopa, homogentisic acid, Dopamine, Dopac and 5-hydroxyindoleacetic acid. This extends the utility of the technology to the realm of metabolomics.

Combining a variety of affinity chemistries with a size-sieving tool in a one-step process could have enormous utility for disease marker discovery and analysis workflows.

In the workflow presented in this study, proteins are denatured when eluted out of particles and then analyzed in mass spectrometry for biomarker discovery. Nevertheless, it is important to note that the harvesting conditions are conducted with native protein mixtures. This permits future applications that require the analytes of interest to be in their native state (immulite, radioimmunoassays). For these applications it would important that proteins are not denatured when released from the particles. Ahmad and colleagues have demonstrated, using circular dichroism, that molecules for drug delivery released from temperature sensitive polymeric particles by temperature changes retained their native conformational state ${ }^{45}$ Consequently possible means of eluting native proteins from the particles include modifying the temperature or $\mathrm{pH}$ of the solution, increasing the ionic strength, or electroeluting the proteins under non denaturing conditions, in the absence of detergent.

\section{Supplementary Material}

Refer to Web version on PubMed Central for supplementary material.

\section{Acknowledgments}

The authors appreciate the generous support of Dr. Vikas Chandhoke and the Department of Life Sciences at George Mason University. The authors also thank Mr. Tom Huff for facilitating experimental procedures. We would like to acknowledge stimulating discussions with Dr. Enrico Garaci, Dr. Alfonso Colombatti, Dr. Claudio Belluco, Dr. Victor Morozov, and Dr. Michele Signore. This work was partly supported by the Italian Istituto Superiore di Sanità in the framework Italy/USA cooperation agreement between the US Department of Health and Human Services and the Italian Ministry of Public Health.

\section{REFERENCES}

1. Aebersold R, Anderson L, Caprioli R, Druker B, Hartwell L, Smith R. J Proteome Res 2005;4(4):11049. [PubMed: 16083259]

2. Srinivas PR, Verma M, Zhao Y, Srivastava S. Clin Chem 2002;48(8):1160-9. [PubMed: 12142368]

3. Frank R, Hargreaves R. Nature reviews 2003;2(7):566-80.

4. Espina V, Mehta AI, Winters ME, Calvert V, Wulfkuhle J, Petricoin EF 3rd, Liotta LA. Proteomics 2003;3(11):2091-100. [PubMed: 14595807]

5. Anderson NL, Anderson NG. Mol Cell Proteomics 2002;1(11):845-67. [PubMed: 12488461]

6. Lopez MF, Mikulskis A, Kuzdzal S, Golenko E, Petricoin EF 3rd, Liotta LA, Patton WF, Whiteley GR, Rosenblatt K, Gurnani P, Nandi A, Neill S, Cullen S, O'Gorman M, Sarracino D, Lynch C, Johnson A, McKenzie W, Fishman D. Clinical chemistry 2007;53(6):1067-74. [PubMed: 17463175]

7. Conrads TP, Hood BL, Veenstra TD. BioTechniques 2006;40(6):799-805. [PubMed: 16774124] 
8. Lowenthal MS, Mehta AI, Frogale K, Bandle RW, Araujo RP, Hood BL, Veenstra TD, Conrads TP, Goldsmith P, Fishman D, Petricoin EF 3rd, Liotta LA. Clin Chem 2005;51(10):1933-45. [PubMed: 16099937]

9. Lopez MF, Mikulskis A, Kuzdzal S, Bennett DA, Kelly J, Golenko E, DiCesare J, Denoyer E, Patton WF, Ediger R, Sapp L, Ziegert T, Lynch C, Kramer S, Whiteley GR, Wall MR, Mannion DP, Della Cioppa G, Rakitan JS, Wolfe GM. Clinical chemistry 2005;51(10):1946-54. [PubMed: 16081505]

10. Zolotarjova N, Martosella J, Nicol G, Bailey J, Boyes BE, Barrett WC. Proteomics 2005;5(13):330413. [PubMed: 16052628]

11. Camerini S, Polci ML, Liotta LA, Petricoin EF, Zhou W. Proteomics Clin. Appl 2007;1:176-184.

12. Geho D, Cheng MM, Killian K, Lowenthal M, Ross S, Frogale K, Nijdam J, Lahar N, Johann D, Herrmann P, Whiteley G, Ferrari M, Petricoin E, Liotta L. Bioconjug Chem 2006;17(3):654-61. [PubMed: 16704202]

13. Tirumalai RS, Chan KC, Prieto DA, Issaq HJ, Conrads TP, Veenstra TD. Molecular \& cellular proteomics 2003;2(10):1096-103. [PubMed: 12917320]

14. Merrell K, Southwick K, Graves SW, Esplin MS, Lewis NE, Thulin CD. Journal of biomolecular techniques 2004;15(4):238-48. [PubMed: 15585820]

15. Orvisky E, Drake SK, Martin BM, Abdel-Hamid M, Ressom HW, Varghese RS, An Y, Saha D, Hortin GL, Loffredo CA, Goldman R. Proteomics 2006;6(9):2895-902. [PubMed: 16586431]

16. Pelton R. Adv Colloid Interface Sci 2000;85(1):1-33. [PubMed: 10696447]

17. Li Y, Tanaka T. The Journal of Chemical Physics 1990;92(2):1365-1371.

18. Jones CD, Lyon LA. Macromolecules 2000;33(22):8301-8306.

19. Moselhy J, Wu XY, Nicholov R, Kodaria K. Journal of Biomaterials Science, Polymer Edition 2000;11(2):123-147. [PubMed: 10718475]

20. Duracher D, Sauzedde F, Elaissari A, Perrin A, Pichot C. Colloid \& Polymer Science 1998;276(3): 219-231.

21. Sershen SR, Westcott SL, Halas NJ, West JL. Temperature-sensitive polymer-nanoshell composites for photothermally modulated drug delivery 2000;51:293-298.

22. Suzuki A, Tanaka T. Nature 1990;346(6282):345-347.

23. Tanaka T, Nishio I, Sun S-T, Ueno-Nishio S. Collapse of Gels in an Electric Field 1982;218:467469.

24. Inomata H, Goto S, Saito S. Phase transition of N-substituted acrylamide gels 1990;23:4887-4888.

25. Kawaguchi H, Fujimoto K, Mizuhara Y. Colloid \& Polymer Science 1992;270(1):53-57.

26. Achiha K, Ojima R, Kasuya Y, Fujimoto K, Kawaguchi H. Interactions between temperature-sensitive hydrogel microspheres and granulocytes 1995;6:534-540.

27. Delair T, Meunier F, Elaissari A, Charles M-H, Pichot C. Colloids and Surfaces A: Physicochemical and Engineering Aspects 1999;153(1-3):341-353.

28. Sparnacci K, Laus M, Tondelli L, Bernardi C, Magnani L, Corticelli F, Marchisio M, Ensoli B, Castaldello A, Caputo A. J Biomater Sci Polym Ed 2005;16(12):1557-74. [PubMed: 16366337]

29. Haruyuki Hiratani YMCA-L. Macromolecular Bioscience 2005;5(8):728-733. [PubMed: 16082622]

30. Nahar M, Dutta T, Murugesan S, Asthana A, Mishra D, Rajkumar V, Tare M, Saraf S, Jain NK. Crit Rev Ther Drug Carrier Syst 2006;23(4):259-318. [PubMed: 17341200]

31. Wu J-Y, Liu S-Q, Heng PW-S, Yang Y-Y. Journal of Controlled Release 2005;102(2):361-372. [PubMed: 15653157]

32. Zhang XZ, Jo Lewis P, Chu CC. Biomaterials 2005;26(16):3299-309. [PubMed: 15603825]

33. Woo BH, Jiang G, Jo YW, DeLuca PP. Pharm Res 2001;18(11):1600-6. [PubMed: 11758769]

34. Basinska T. Macromol Biosci 2005;5(12):1145-68. [PubMed: 16294370]

35. Saunders BR, Vincent B. Advances in Colloid and Interface Science 1999;80(1):1-25.

36. Pecora, R. Dynamic Light Scattering: Applications of Photo Correlation Spectroscopy. Springer; 1985. p. 436

37. Fernandez-Nieves A, Fernandez-Barbero A, Vincent B, de las Nieves FJ. Macromolecules 2000;33:2114-2118.

38. Ito S, Ogawa K, Suzuki H, Wang B, Yoshida R, Kokufuta E. Langmuir 1999;15(12):4289-4294. 
39. Boschetti E. Journal of Chromatography A 1994;658(2):207-236.

40. Eppley BL, Woodell JE, Higgins J. Plastic and reconstructive surgery 2004;114(6):1502-8. [PubMed: 15509939]

41. Gulmann C, Sheehan KM, Kay EW, Liotta LA, Petricoin EF 3rd. The Journal of pathology 2006;208 (5):595-606. [PubMed: 16518808]

42. Ayache S, Panelli M, Marincola FM, Stroncek DF. American journal of clinical pathology 2006;126 (2):174-84. [PubMed: 16891190]

43. Noda Y, Fujiwara K, Yamamoto K, Fukuno T, Segawa S-I. Specificity of trypsin digestion and conformational flexibility at different sites of unfolded lysozyme 1994;34:217-226.

44. Ivanov AE, Galaev IY, Mattiasson B. Journal of molecular recognition 2006;19(4):322-31. [PubMed: 16865663]

45. Ahmad H, Okubo M, Kamatari YO, Minami H. Colloid \& Polymer Science 2002;280(4):310-315. 


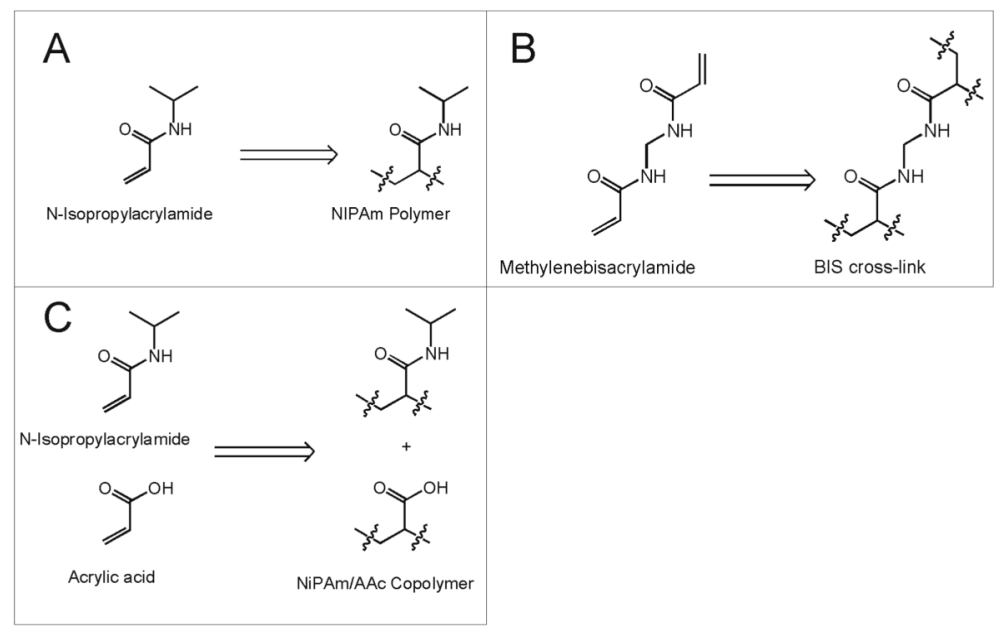

Figure 1.

Chemical composition of particles. Structure of (A) N-isopropylacrylamide (NIPAm) and its polymer, (B) methylenebisacrylamide and (C) NIPAm and acrylic acid and their polymers. 


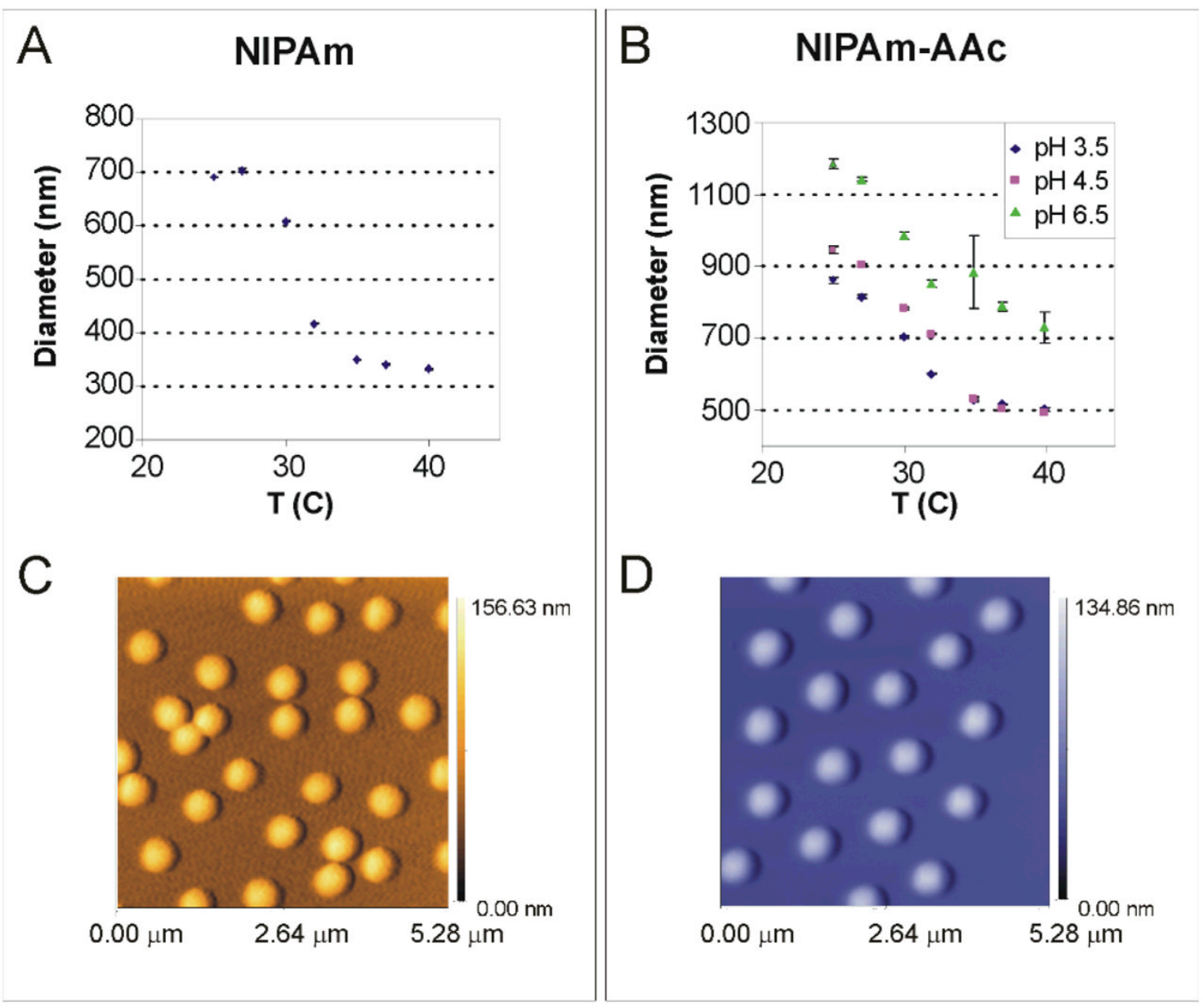

Figure 2.

Particle characterization. (A) Light scattering measurement of NIPAm particle size as a function of temperature (diameter decreases as temperature increases). (B) Plots of correlation of the size of NIPAm/AAc particles with temperature (diameter decreases as temperature increases) and $\mathrm{pH}$ (diameter decreases as $\mathrm{pH}$ decreases). AFM images of (C) NIPAm particles and (D) NIPAm/AAc particles on mica. 


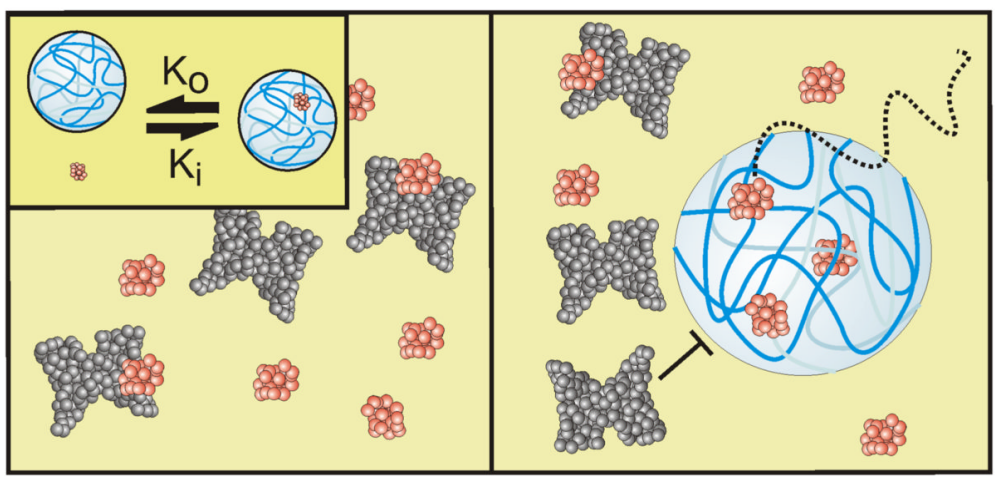

Figure 3.

Schematic drawing of molecular sieving of particles in solution. Low molecular weight proteins are harvested; high molecular weight proteins are excluded. 

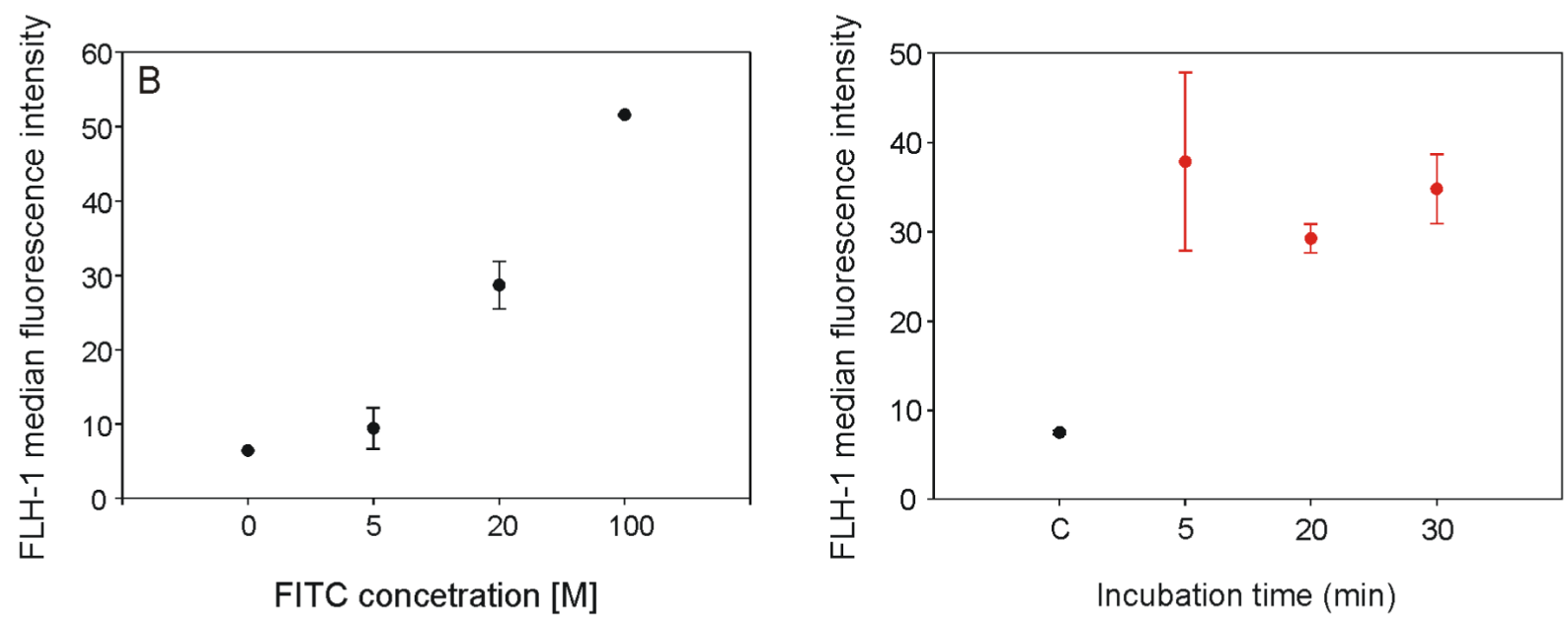

Figure 4.

Flow cytometry analyses of FITC-incubated particles. (A) Uptake is dose dependent. (B) Uptake rapidly reaches saturation with FITC concentration of $20 \mu \mathrm{M}$. 


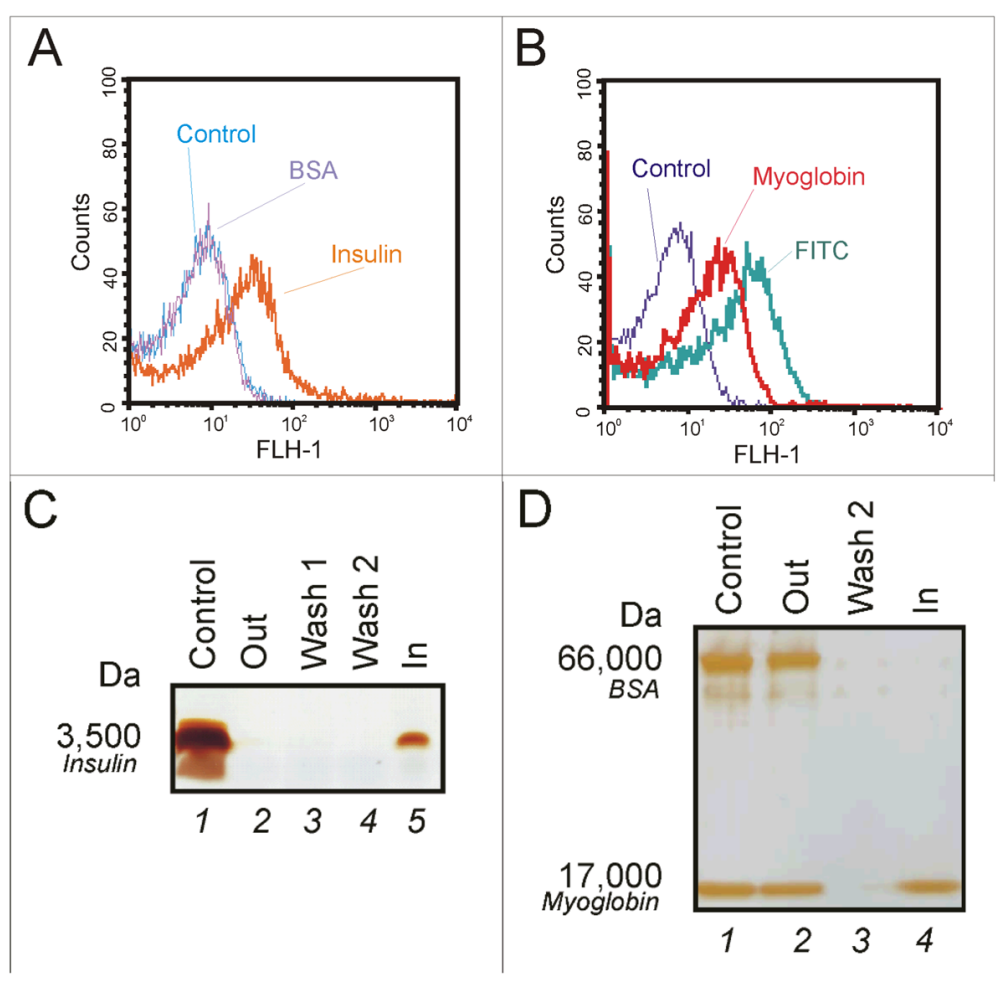

Figure 5.

NIPAm particles incubated with FITC and FITC-labeled proteins: Flow cytometry measurements of (A) BSA and insulin, (B) myoglobin and free FITC. (C) SDS-PAGE of particles incubated with insulin: Lane 1) insulin solution (Control), 2) NIPAm supernatant (Out, substance excluded from the particles), 3) wash 1, 4) wash 2, 5) NIPAm particles (In, substance captured by the particles). (D) SDS-PAGE of NIPAm particles incubated with BSA and myoglobin: 1) BSA and myoglobin (Control), 2) NIPAm supernatant (Out), 3) wash 2, 4) NIPAm particles (In). BSA is totally excluded. 


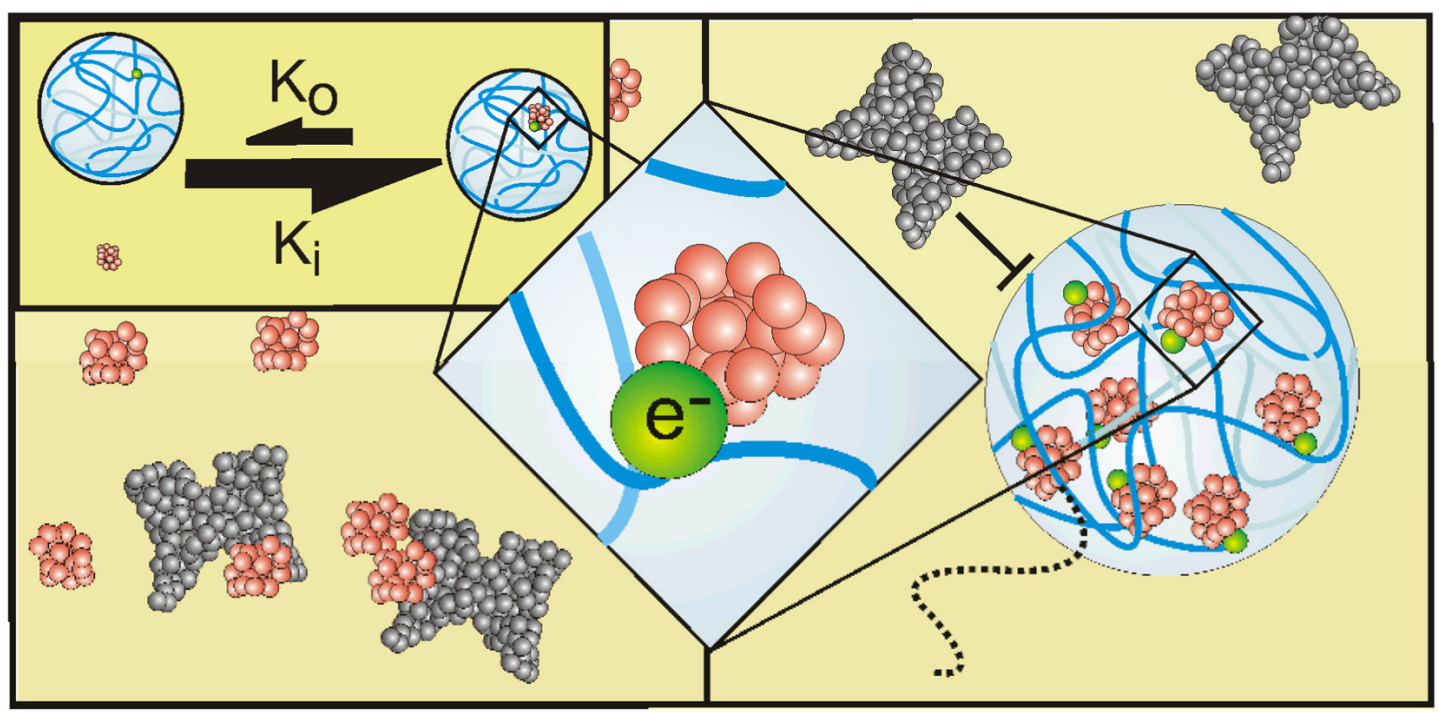

Figure 6.

Schematic depiction of affinity-based sequestering. 


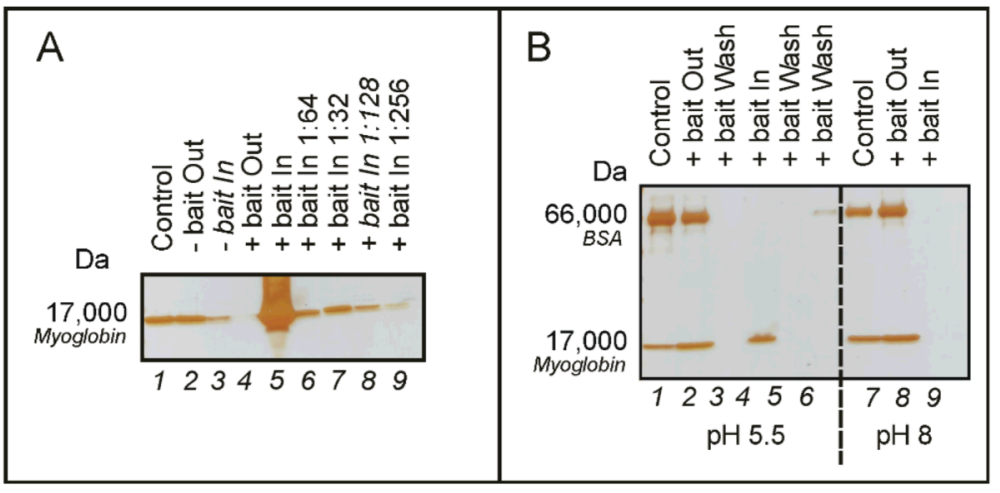

Figure 7.

Protein sequestering by NIPAm/AAc particles (+ bait ) versus NIPAm particles (- bait), SDSPAGE analysis of (A) Myoglobin (aqueous solution, $\mathrm{pH}$ 5.5) sequestration by particles + and - bait. Lane 1) myoglobin, 2) NIPAm supernatant (Out), 3) NIPAm particle (In), 4) NIPAm/ AAc supernatant (Out), 5) NIPAm/AAc particle (In), 6) NIPAm/AAc particles 1:64, 7) NIPAm/AAc particles 1:32,8) NIPAm/AAc particles 1:128, and 9) NIPAm/AAc particles 1:256. (B) BSA and myoglobin sequestration by particles+bait (NIPAm/AAc) at two $\mathrm{pH}$ values. Lane 1) BSA and myoglobin, $\mathrm{pH} 5.5,2$ ) NIPAm/AAc supernatant (Out) pH 5.5, 3) wash $3 \mathrm{pH} 5.5,4$ ) NIPAm/AAc particles (In) $\mathrm{pH} 5.5,5$ ) wash $2 \mathrm{pH} \mathrm{5.5,6)} \mathrm{wash} 1 \mathrm{pH} \mathrm{5.5,7)}$ BSA and myoglobin, pH 8, 8) NIPAm/AAc supernatant (Out) pH 8, and 9) NIPAm/AAc particles (In) $\mathrm{pH} 8$. 


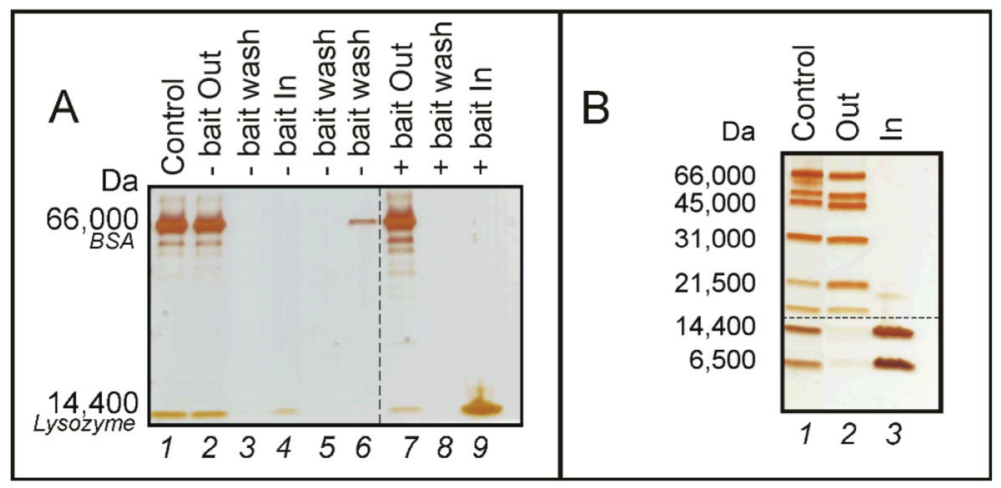

Figure 8.

(A) SDS-PAGE analysis of particles- and +bait incubated with BSA and lysozyme: Lane 1) BSA and lysozyme solution prior to particle introduction, 2) NIPAm (- bait) supernatant (Out), 3) wash 3, 4) NIPAm (- bait) particles (In), 5) wash 2, 6) wash 1, 7) NIPAm/AAc (+ bait) supernatant (Out), 8) wash 3, and 9) NIPAm/AAc (+ bait) particles (In). (B) SDS-PAGE analysis of NIPAm/AAc particles (+ bait) incubated with molecular weight (MW) markers: 1) MW markers, 2) NIPAm/AAc supernatant (Out), and 3) NIPAm/AAc particles (In). 


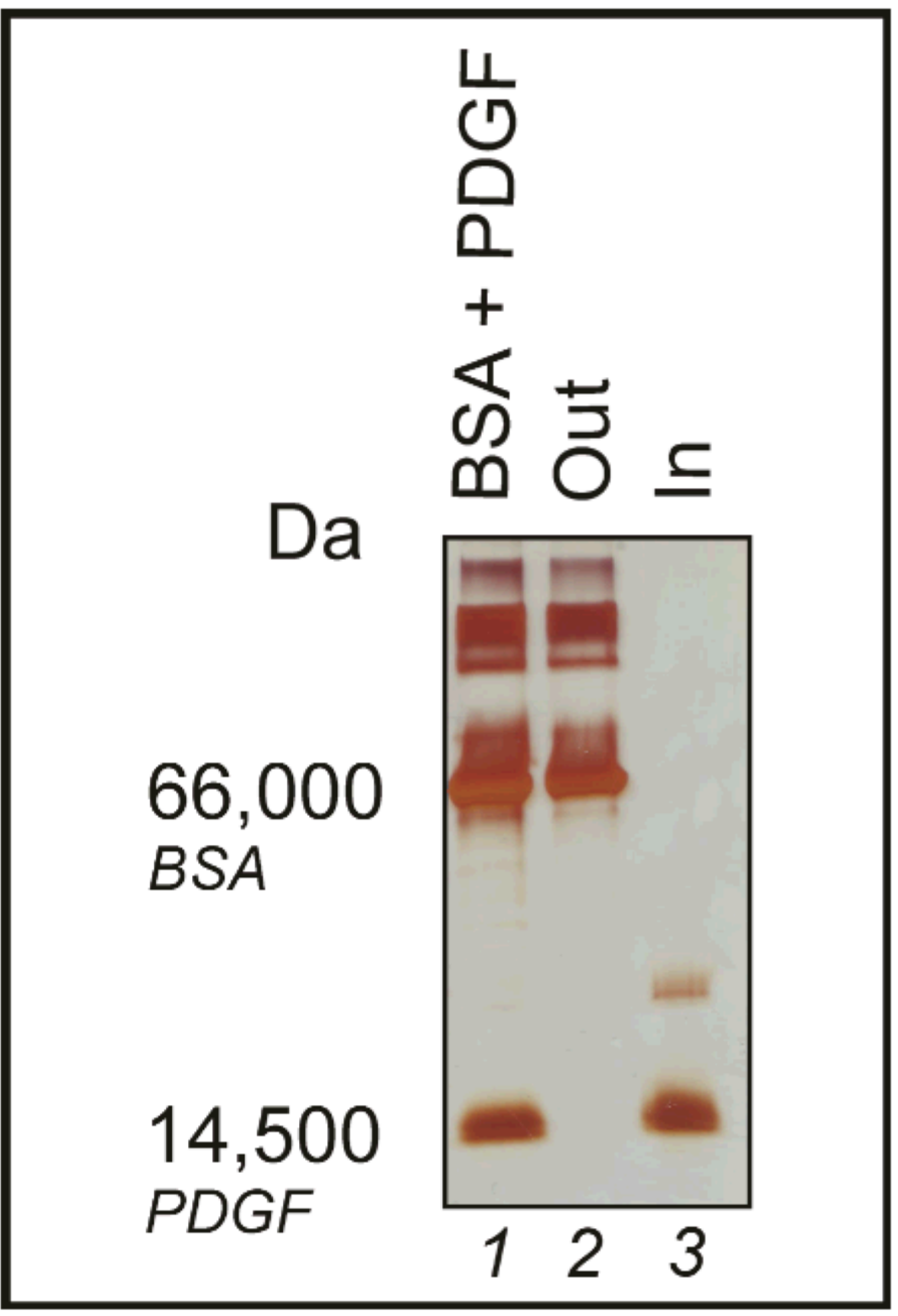

Figure 9.

SDS PAGE analysis of particles + bait incubated with PDGF B and BSA. Lane 1) BSA and PDGF B, 2) NIPAm/AAc supernatant (Out), 3) NIPAm/AAc particles (In). 


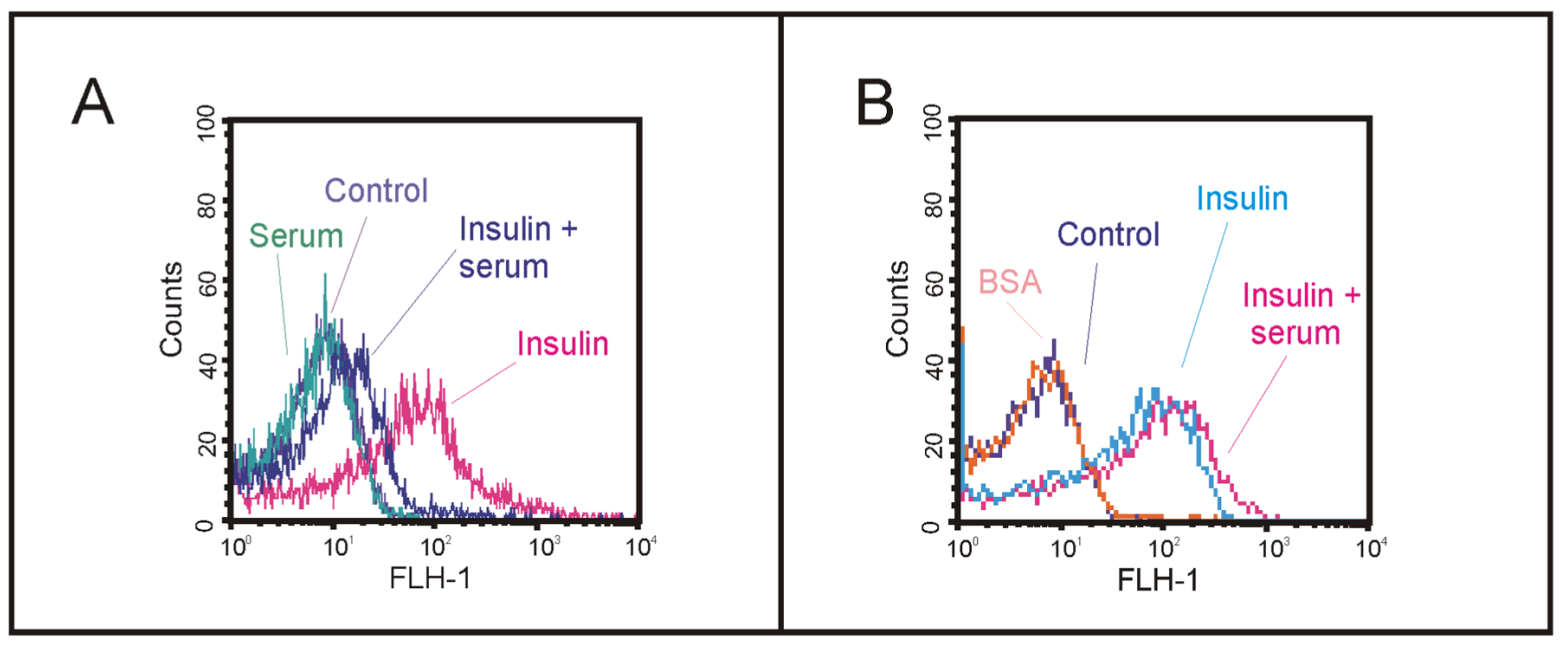

Figure 10.

Flow cytometry analysis of (A) NIPAm and (B) NIPAm/AAc particles incubated with FITClabeled insulin aqueous solution and FITC-labeled insulin spiked in serum, respectively. 

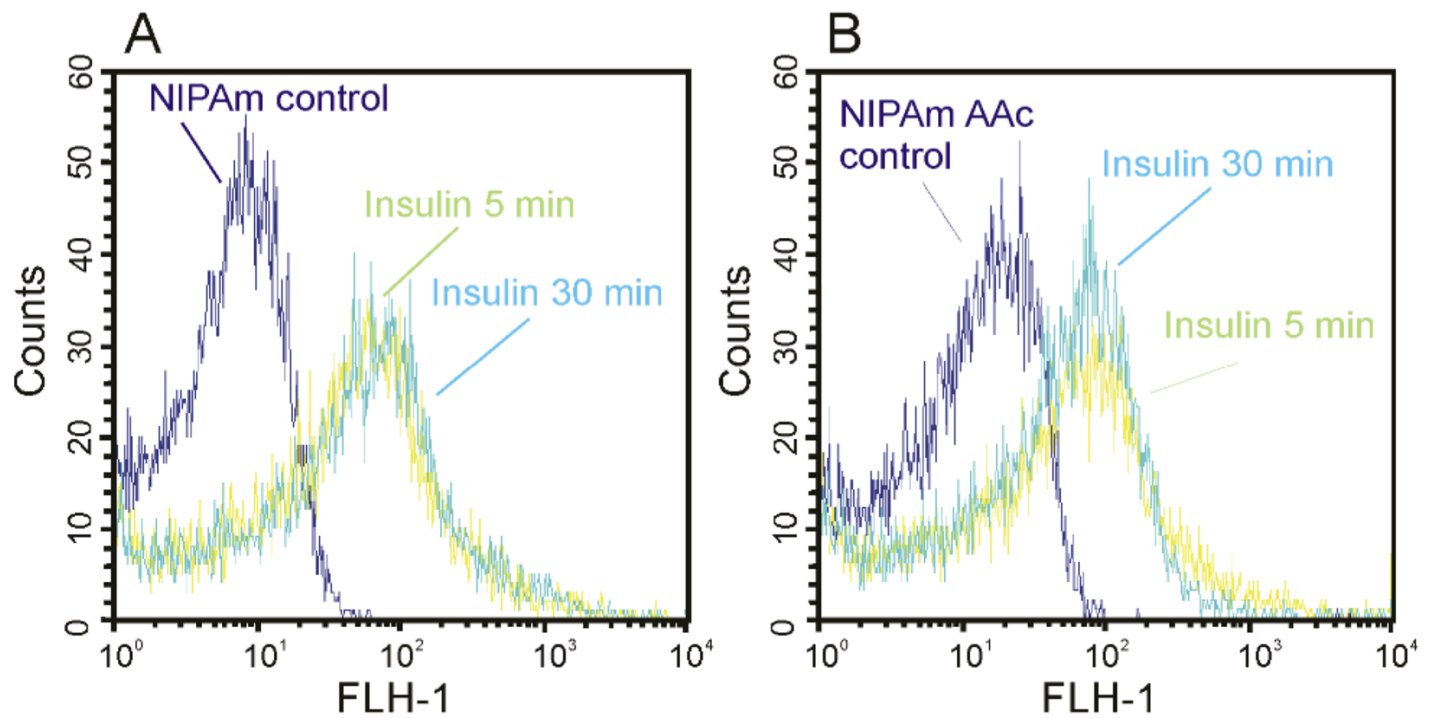

Figure 11.

Flow cytometry time course studies of (A) NIPAm and (B) NIPAm/AAc particles incubated with FITC-labeled insulin. 


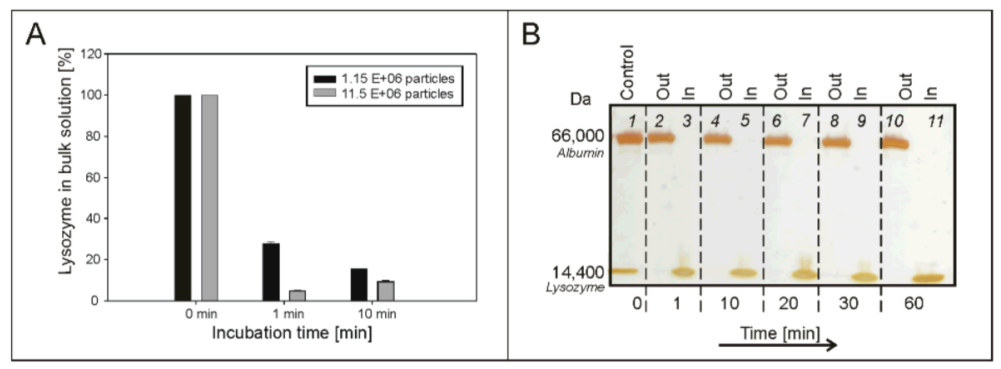

Figure 12.

Uptake time course study (A) Mean values of the percentage, relative to the initial amount, of lysozyme in solution incubated with two quantities of NIPAm/AAc particles as measured by RPPAs (three replicate analyses and standard deviation shown). (B) SDS-PAGE analysis of a lysozyme and BSA solution incubated with NIPAm/AAc particles. Lane 1) BSA and lysozyme solution. 2-11) alternating supernatant (Out) and particles (In) for each of 5, 10, 20, 30, and 60 minutes incubation times. Lysozyme uptake is rapid and complete, while BSA exclusion is total. 


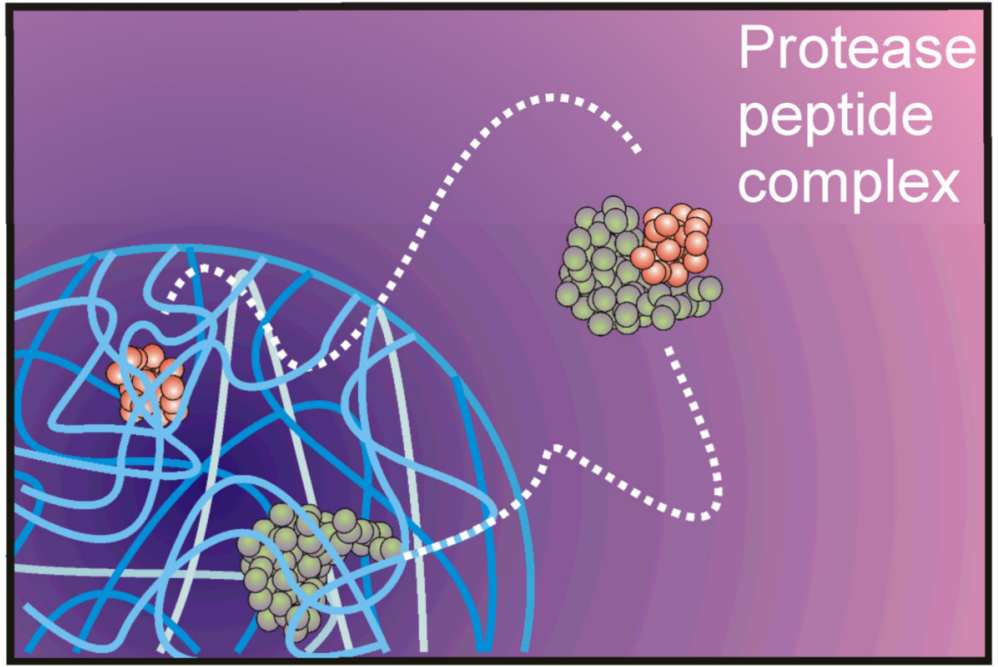

Figure 13.

Schematic drawing illustrating the ability of particles to protect proteins from enzymatic degradation. 


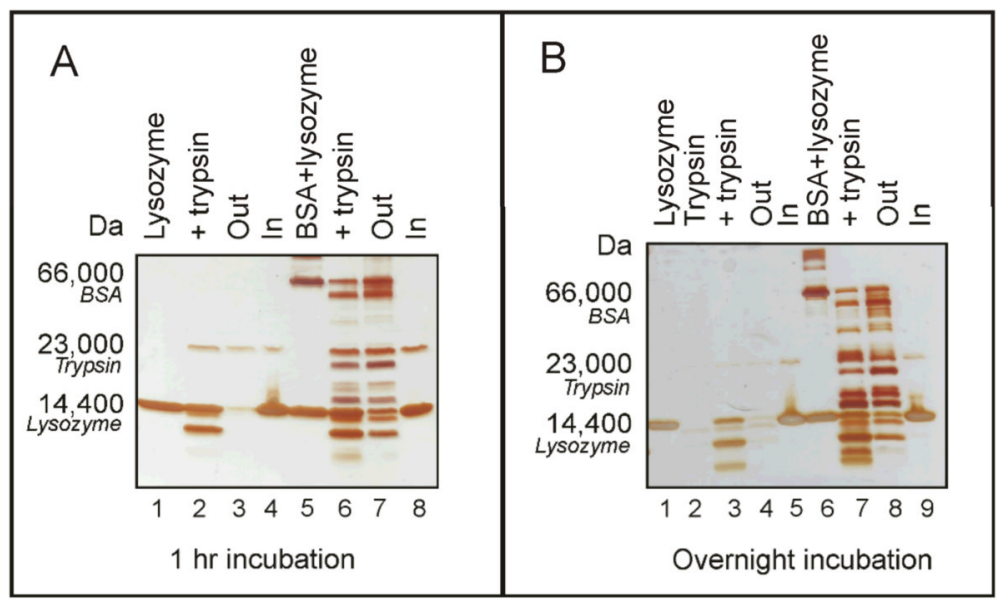

Figure 14.

NIPAm/AAc particles (+ bait) protect bound proteins from degradation by enzymes that may be present. (A) NIPAm/AAc particles incubated with a solution containing lysozyme and trypsin for $1 \mathrm{hr}$ : Lane 1) lysozyme, 2) lysozyme incubated with trypsin, 3) NIPAm/AAc supernatant (Out), 4) NIPAm/AAc particles (In), 5) BSA and lysozyme, 6) BSA and lysozyme + protease, 7) NIPAm/AAc particles supernatant (Out), and 8) NIPAm/AAc particles (In). (B) NIPAm/AAc particles incubated overnight with BSA, lysozyme, and trypsin: Lane 1) lysozyme, 2) trypsin, 3) lysozyme + trypsin, 4) NIPAm/AAc supernatant (Out), 5) NIPAm/ AAC particles (In), 6) lysozyme and BSA, 7) BSA and lysozyme + protease, 8) NIPAm/AAc supernatant (Out), and 9) NIPAm/AAc particles (In). 

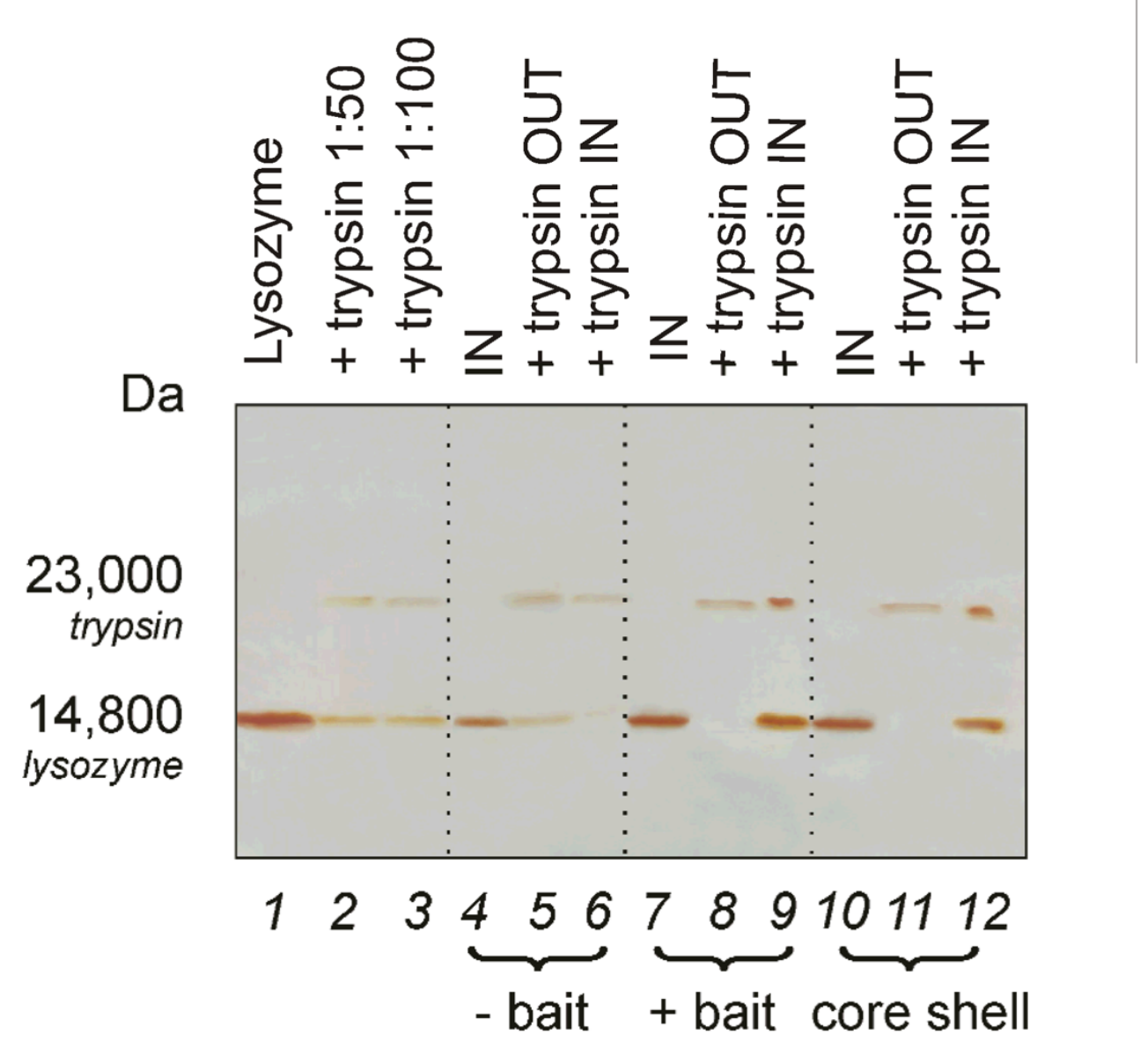

Figure 15.

SDS PAGE analysis of reduced and alkylated lysozyme exposed to tryptic digestion and incubated with particles - bait, + bait, and core shell. Lane 1) reduced and alkylated lysozyme, 2) lysozyme + trypsin 1:50,3) lysozyme + trypsin 1:100, 4) lysozyme with NIPAm particles (In), 5) lysozyme + trypsin + NIPAm particles supernatant (Out), 6) lysozyme + trypsin + NIPAm particles (In), 7) lysozyme + NIPAm/AAc particles (In), 8) lysozyme + trypsin + NIPAm/AAc particles supernatant (Out), 9) lysozyme + trypsin + NIPAm/AAc particles (In), 10) lysozyme + core shell (In), 11) lysozyme + trypsin + core shell particles supernatant (Out), 12) lysozyme + trypsin + core shell particles (In). 


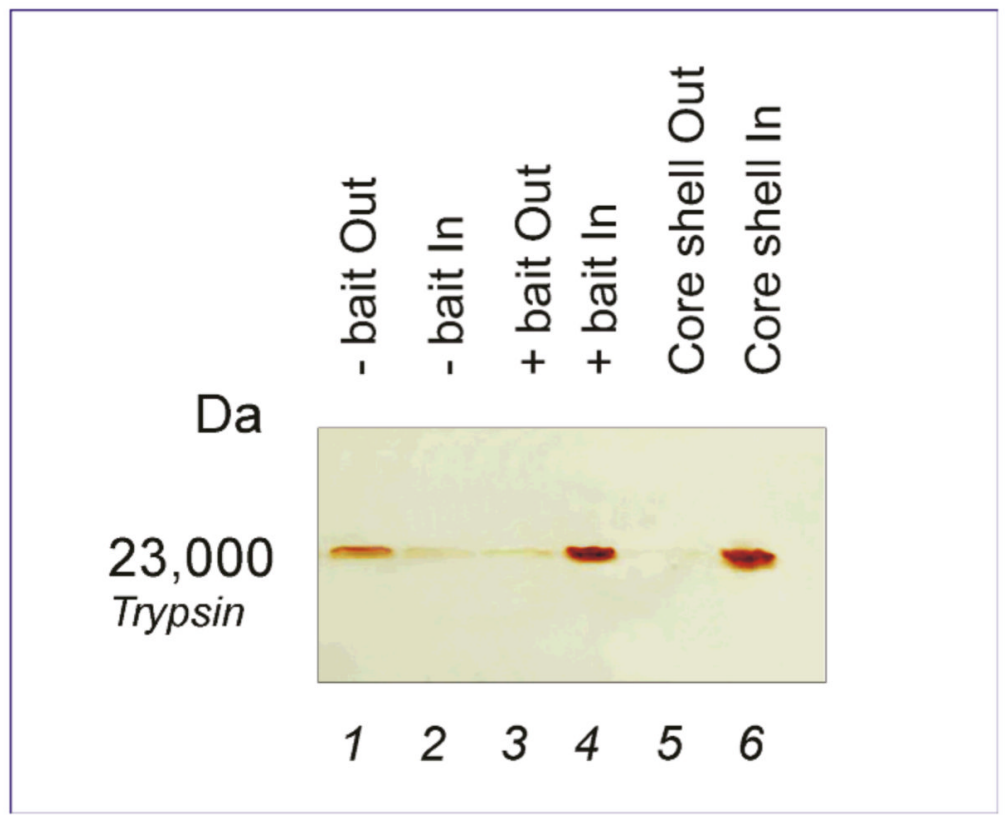

Figure 16.

SDS PAGE analysis of trypsin incubated with NIPAm, NIPAm/AAc and core shell particles. Trypsin incubated with Lane 1) - bait particles, supernatant (Out), 2) - bait particles (In), 3) + bait particles, supernatant (Out), 4) + bait particles (In), 5) core shell particles, supernatant (Out), 6) core shell particles (In). 


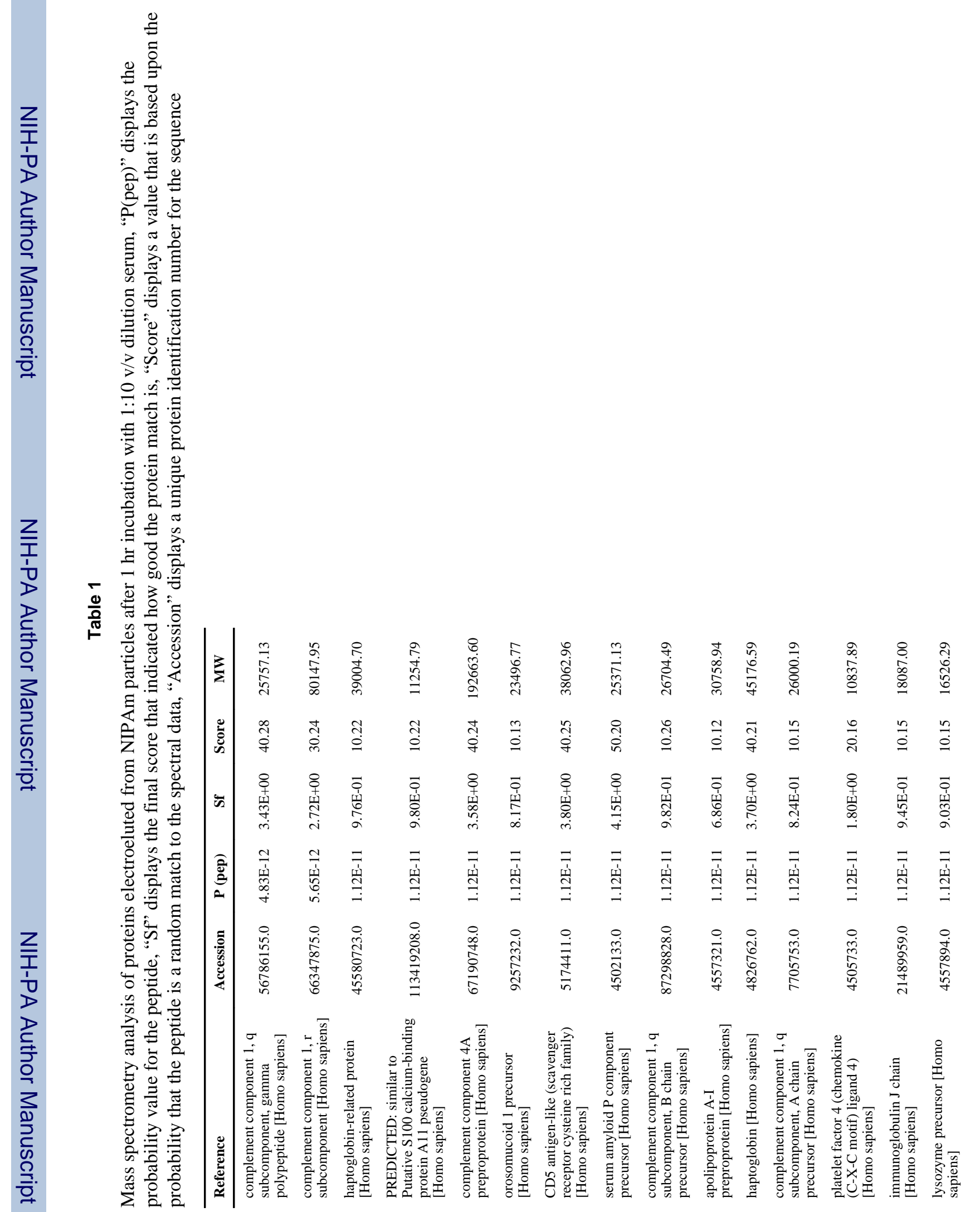




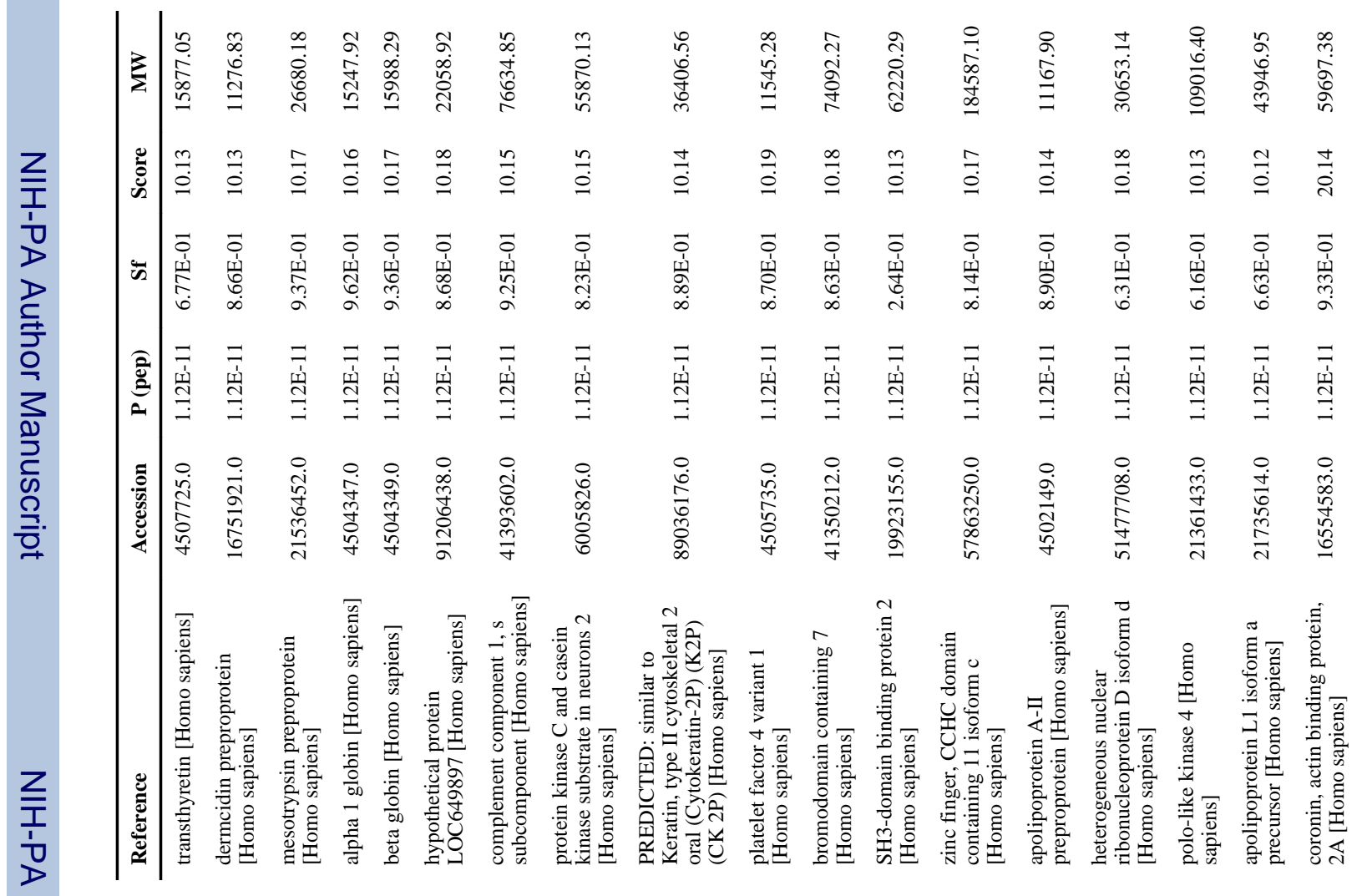


$\stackrel{\Xi}{\Xi}$

公

常

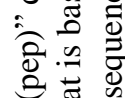

원

ह气

它

.ํㅣㄹ

吾

$>$

은

돈.

उ

흐 สำ

ํํㄱ. 


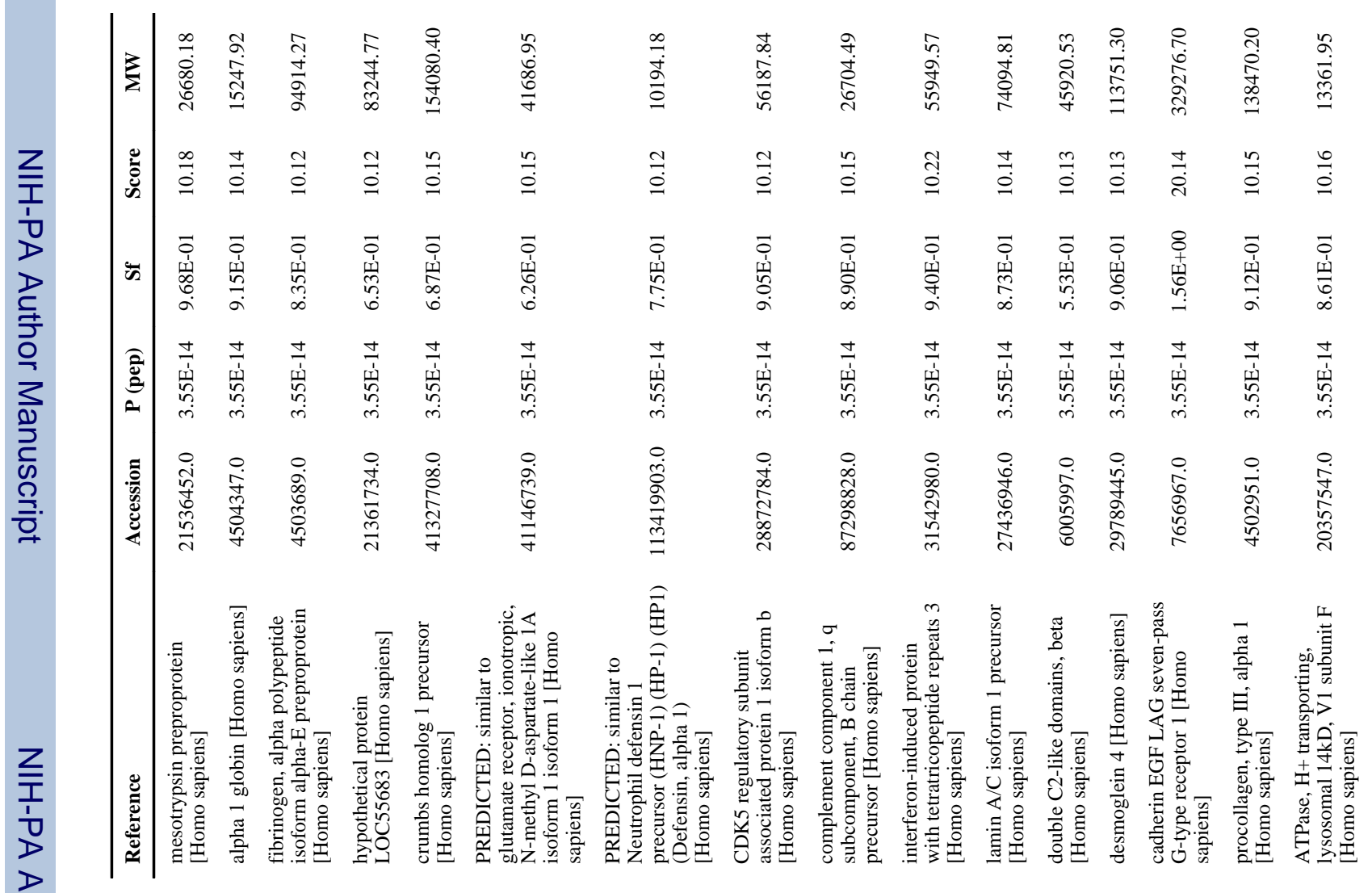

